\title{
Grain Refinement of $\alpha$-iron by Repeated Carburizing and Decarburizing Reactions
}

\author{
In-Hyeon JEONG, Jae-Sang LEE, Sung-Mo JUNG, Jang-Gyu KIM and Yasushi SASAKI \\ Graduate Institute of Ferrous Technology (GIFT), Pohang University of Science and Technology (POSTECH), Hyo-ja dong, \\ Nam gu, Pohang, 790-784 Korea (South).
}

(Received on September 29, 2010; accepted on January 31, 2011)

\begin{abstract}
The grain refinement of $\alpha$-Fe using repeated carburizing and decarburizing at $1073 \mathrm{~K}$ are investigated. It is found that the grain sizes are decreased by carburizing reaction but are increased by decarburizing reaction. Repeated $\alpha \leftrightarrow \gamma$ phase transformations make grain size smaller. However, without pinning elements, the reduction of the grain size has limitation. Sulfur does not have enough effects on the grain growth with the grain size of less than $30 \mu \mathrm{m}$. To improve the grain refinement process, $\mathrm{Fe}_{3} \mathrm{C}$ was introduced by annealing at $873 \mathrm{~K}$ along with the carburizing and decarburizing processing. Formed $\mathrm{Fe}_{3} \mathrm{C}$ can supply a lot of nucleation site for austenite nuclei during the reaustenitizing and retards ferrite grain growth during $\gamma \rightarrow \alpha$ transformation by the decarburization reaction. The fine uniform grains of less than $10 \mu \mathrm{m}$ have been produced by the carburizing and decarburizing processing at $1073 \mathrm{~K}$ along with adjusting the cementite size and the whole volume during the heat treatment at $873 \mathrm{~K}$.
\end{abstract}

KEY WORDS: grain refinement; carburization; de-carburization; reaustenitizing; solute drag effect; cementite.

\section{Introduction}

It has been $\mathrm{known}^{1)}$ that the yield strength of pure metals and single-phase alloys increase linearly with [Mean grain size $]^{-1 / 2}$. Thus, the attainment of finer ferrite grain structure in low carbon steel has been extensively studied because the fine ferrite grain is predicted to have significantly higher yield strengths, lower ductile-brittle transition temperatures as the grain sizes are smaller. ${ }^{2}$

Up to until now, the conventional ways to refine the grain sizes usually use thermo-mechanical processes. The combinations of the controlled rolling and the controlled heat treatment have been considered to be the most effective methods to produce the refined ferrite grain structures. ${ }^{2)}$ Conventional thermo-mechanical controlled process (TMCP) and severe plastic deformations are the representative methods of the grain refinement techniques.

In 1971, Grange ${ }^{3)}$ demonstrated that the austenite grain sizes of medium and high carbon steels could be reduced to about $5 \mu \mathrm{m}$ by multi-cycled rapid austenitizing and quenching through the $A_{1}$ to $A_{3}$ range. His results showed the clear evidences of the grain refinement possibility by the rapid heating process. This method is, however, only applicable for medium (more than 0.5 mass $\%$ C) and high carbon steels. In addition, the rapid heating and quenching cycles within a short time may not suitable for a practical production line.

$\alpha-\gamma$ phase transformation in steel does occur not only by temperature change but also by carbon content change. Figure 1 illustrates the direction of $\alpha-\gamma$ phase transformations due to temperature change and carbon content change,

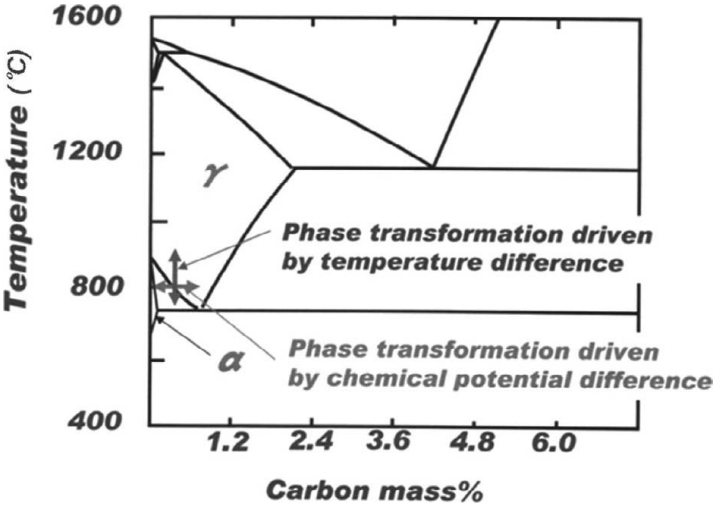

Fig. 1. Fe-C phase diagram.

respectively. Changing the carbon content in steel can be achieved by carburization and decarburization reactions. Thus, as a possible alternative grain refinement process, the grain refinement of $\alpha$-Fe by multi-cycled carburizing and decarburizing reactions is investigated in this study.

\section{Experimental}

Two groups of carbon steels were used in this experiment. One group was ultra low carbon steels whose sulfur contents are 9, 20 and 58 mass ppm, respectively. The other group was the commercial mild steel which contained 0.45 mass $\%$ carbon, 0.7 mass $\%$ manganese and 0.2 mass $\%$ silicon. The chemical compositions are shown in Table 1. Each specimen was cut into the dimension of $5 \mathrm{~mm} \times 5 \mathrm{~mm} \times 0.5 \mathrm{~mm}$, and the one side of the specimen was ground by using $\mathrm{SiC}$ 
papers and polished by using 3.0, 1.0 and $0.1 \mu \mathrm{m}$ diamond pastes.

In the present study, two experimental systems were used. Both systems were essentially the same except the furnace. One was an image furnace coupled with a confocal laser scanning microscope (CLSM). The image furnace was used for the observation of the phase transformation. Other was a conventional horizontal resistance furnace and was used to carry out the multi-cycled carburizing and decarburizing reactions combined with the heat treatment of specimen. The experimental set up with the resistance furnace is shown in Fig. 2.

$\mathrm{Ar}, \mathrm{H}_{2}, \mathrm{CO}$ and $\mathrm{CO}_{2}$ gases were purified by drierite $\left(\mathrm{CaSO}_{4}\right)$ and $\mathrm{Mg}$ de-oxidation furnace (at $\left.723 \mathrm{~K}\right)$. The each flow rate of gases was controlled by using mass flow rate controllers. $\mathrm{CO}-\mathrm{CO}_{2}$ gas mixture gas was used for carbur-

Table 1. Chemical compositions of the ultra low carbon steels prepared and the commercial steel (unit : mass ppm)

\begin{tabular}{crrrrrrrr}
\hline Unit: massppm & $\mathrm{C}$ & $\mathrm{Cr}$ & $\mathrm{N}$ & $\mathrm{O}$ & $\mathrm{P}$ & $\mathrm{S}$ & $\mathrm{Si}$ & $\mathrm{Mn}$ \\
\hline SpecimenA & 35 & 2 & 9 & 150 & 9 & 9 & 50 & $<10$ \\
SpecimenB & 40 & $<10$ & $<10$ & $<100$ & 17 & 20 & 100 & $<400$ \\
SpecimenC & 10 & 48 & $<10$ & $<100$ & $<10$ & 58 & 48 & $<600$ \\
SpecimenD & 4500 & & & & & & 2000 & 7000 \\
\hline
\end{tabular}

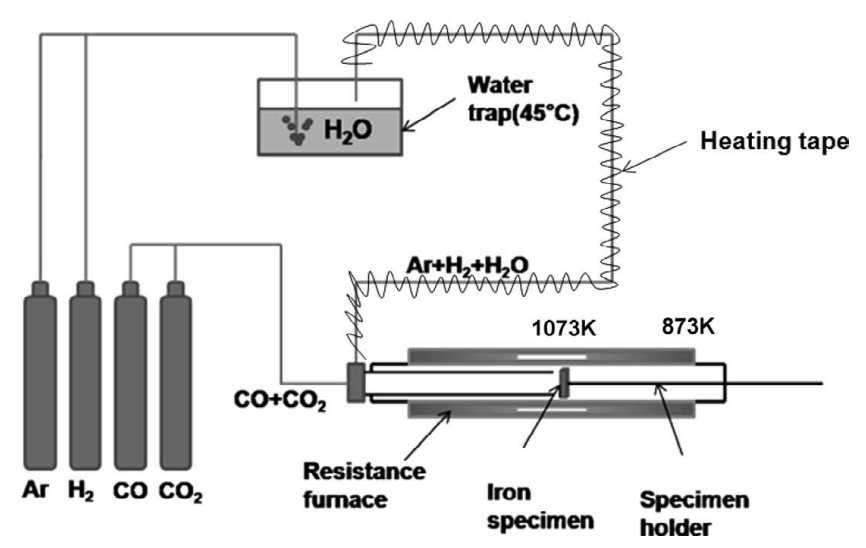

Fig. 2. Schematic illustration of experimental apparatus by carburizing and decarburizing reactions. izing reactions and $\mathrm{Ar}-\mathrm{H}_{2} \mathrm{O}$ or $\mathrm{H}_{2}-\mathrm{H}_{2} \mathrm{O}$ gas mixture was used for decarburizing reactions. The $\mathrm{H}_{2} \mathrm{O}-\mathrm{H}_{2}$ or $\mathrm{H}_{2} \mathrm{O}-\mathrm{Ar}$ mixtures were produced by bubbling $\mathrm{H}_{2}$ or Ar gas in a water bath held at fixed temperature. The partial pressure of $\mathrm{H}_{2} \mathrm{O}$ was controlled by changing the temperature of the water bath. In order to prevent the condensation of $\mathrm{H}_{2} \mathrm{O}$ before it reached the furnace, $\mathrm{H}_{2} \mathrm{O}$ gas delivery tube from the water trap to the furnace was heated by heating tapes.

The phase transformation between $\alpha$ and $\gamma$ phase was observed by the confocal laser scanning microscope (CLSM). The specimen $(10 \times 10 \mathrm{~mm})$ was put on the $\mathrm{Pt}$ specimen holder in the image furnace of CLSM. Purging $\mathrm{Ar}-2 \% \mathrm{H}_{2}$ mixing gas was introduced to the furnace for $30 \mathrm{~min}$. After that, the specimen was heated up to $1073 \mathrm{~K}$ and was held for a particular time to adjust the grain size of specimen. For example, the grain size of $200 \mu \mathrm{m}$ was obtained by 5 minutes treatment. $\mathrm{CO}-3 \mathrm{vol} \% \mathrm{CO}_{2}$ mixture gas was injected for $3 \mathrm{~min}$ to carburize the surface. Then, $\mathrm{Ar}-45 \mathrm{vol} \% \mathrm{H}_{2}-10 \mathrm{vol} \% \mathrm{H}_{2} \mathrm{O}$ mixture gas was injected for $3 \mathrm{~min}$ to decarburize it. If necessary, this carburization and decarburization were repeated.

Figure 3 illustrates the experimental procedure schematically. After finishing $1^{\text {st }}$ step of carburizing and decarburizing, either the other step could be carried out again as many as needed or the experiment could be finished by quenching. For example, in Fig. 3(a), the experiment procedure could be either (1) $\rightarrow$ (2) $\rightarrow$ (3) $\rightarrow$ quenching or (1) $\rightarrow$ (2) $\rightarrow$ (3) $\rightarrow$ (1) $\rightarrow$ (2) $\rightarrow$ (3) $\rightarrow$ quenching and so on.

The total flow rate of both carburizing and decarburizing gases were $300 \mathrm{ml} / \mathrm{min}$. After the reaction treatments, the sample was quenched by introducing He gas and power off. The surface of the quenched specimen was grinded by using 400, 800, 1200, 2000 mesh silica papers and polished by using $1 \mu \mathrm{m}$ diamond paste. It was etched by using $3 \%$ nital etching solution and observed by the optical microscope.

Figure 4 illustrates the experimental procedure with heat treatment schematically. The conditions of carburizing and decarburizing gases were the same to the one without heat treatment. In the heat treatment process, the specimen was cooled to $673 \mathrm{~K}$ or $873 \mathrm{~K}$ and held for 5 minutes to form the cementite in the pearlite structure after finishing the carburizing reaction. After the cementite forming, the specimen

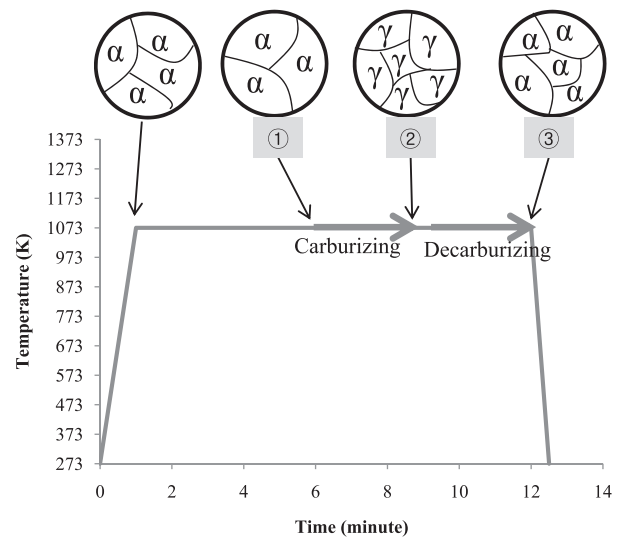

(a)

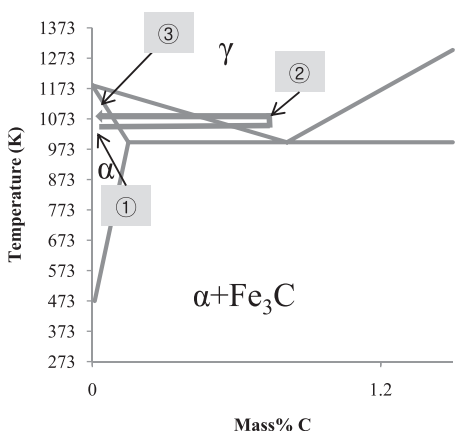

(b)

Fig. 3. $\alpha \rightarrow \gamma \rightarrow \alpha$ phase transformation due to carburizing and decarburizing reactions. (a) Schematic diagram of heat pattern during carburizing and decarburizing processing. (b) Grain refinement processing path in $\mathrm{Fe}-\mathrm{C}$ diagram. 


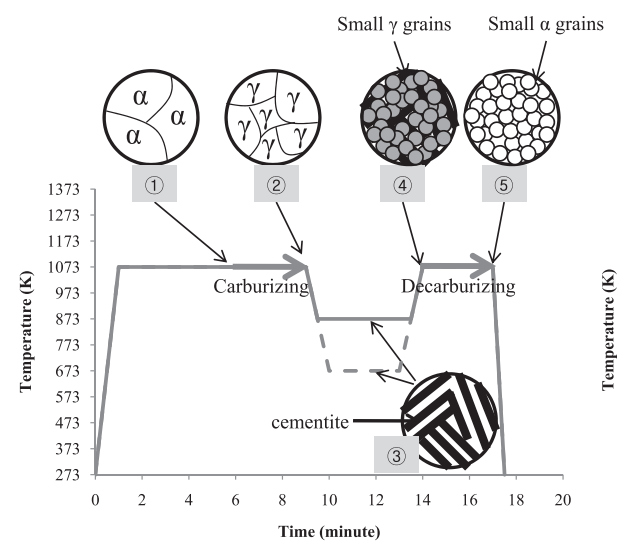

(a)

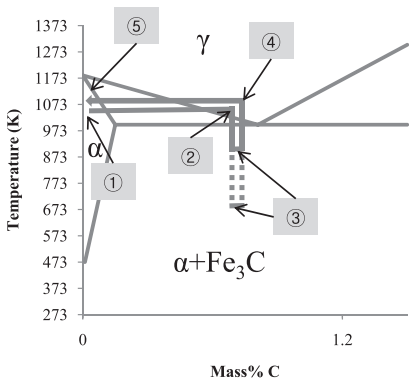

(b)

Fig. 4. $\alpha \rightarrow \gamma \rightarrow \alpha$ phase transformation due to carburizing and decarburizing reactions. (a) Schematic diagram of heat pattern during carburizing and decarburizing processing along with annealing processing. (b) Grain refinement processing path in $\mathrm{Fe}-\mathrm{C}$ diagram.

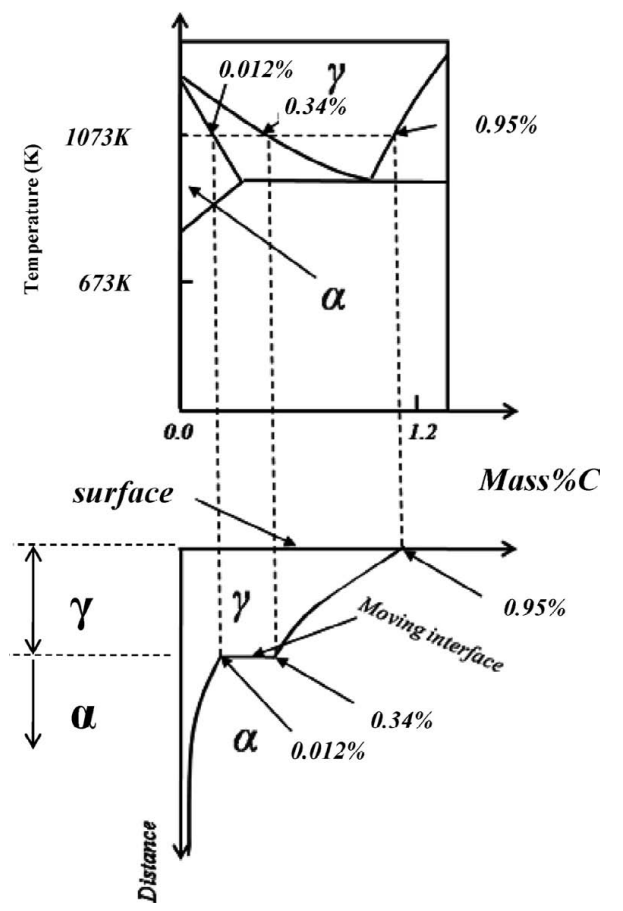

Fig. 5. Schematic diagram of $\gamma$ phase development by carburizing process at $1073 \mathrm{~K}$.

was heated up to $1073 \mathrm{~K}$ again (reaustenitizing) and decarburized for 3 minutes, then quenched.

\section{Results and Discussion}

\section{1. $\gamma$ phase Development in $\alpha$ Phase Matrix by Car- burization Reaction}

$\alpha-\gamma$ phase transformation by carburizing and decarburizing occurs through carbon diffusion process in steel matrix. Figure 5 illustrates how $\alpha-\gamma$ phase transformation occurs due to the carburizing reaction at surface. When the surface carbon concentration in $\alpha$ phase reaches to $0.012 \%$ by the carburization reaction, $\gamma$ phase comes to appear at the surface. The depth of $\gamma$ phase region $(0.34 \%-0.95 \% \mathrm{C})$ from the surface will gradually increase with carburization time.

The thickness of $\gamma$ phase formed by carburizing reaction

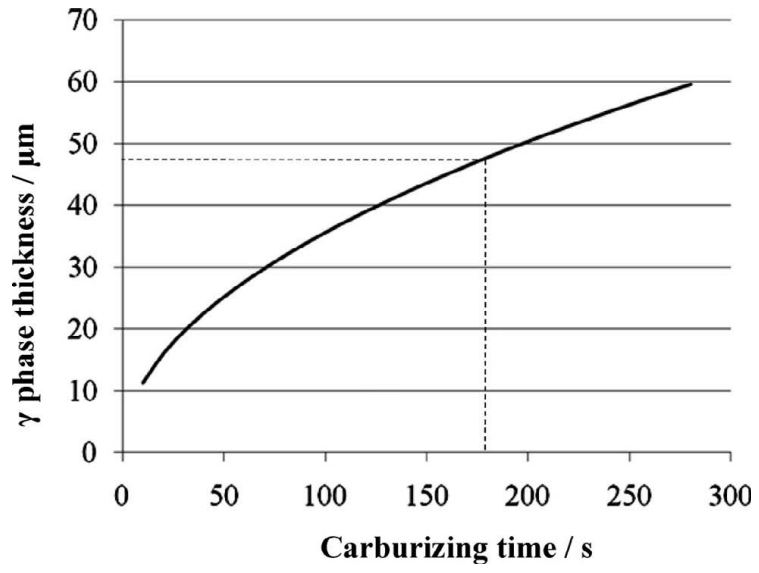

Fig. 6. Effect of the thickness of $\gamma$ phase on carburizing reactions.

at $1073 \mathrm{~K}$ with time was calculated assuming the $\mathrm{C}$ diffusion process as rate controlling step. ${ }^{4)}$ The boundary conditions were obtained from the iron-carbon phase diagram as that shown in Fig. 5. The surface concentration of carbon can be determined by the supply and removal rate of carbon at the surface. In the present calculation, the saturated $\mathrm{C}$ is assumed since the $\mathrm{C}$ diffusion rate will be much slower than that of carburization reaction rate.

Figure 6 shows the calculated the thickness development of $\gamma$ phase at $1073 \mathrm{~K}$. The line shows the thickness of the formed $\gamma$ phase from the surface. From the calculated results, the position of the $\alpha / \gamma$ interface from the specimen surface after 3 minutes carburizing reaction is about $45 \mu \mathrm{m}$. If the carburizing reaction time is increased, the thickness of $\gamma$ phase can increase. However, with the effect of alloys and with the difficulties of experimental setup, the depth of the moving interface is less than the calculation value. The purpose of the present study is to confirm the feasibility of the grain refinement by the repeated carburizing and decarburizing reactions. The depth of the moving interface was not severely considered. Thus, in the present study, the carburizing and decarburizing reaction time is fixed to $3 \mathrm{~min}$. 


\subsection{Surface Observation Of Repeated Carburizing and Decarburizing Reactions}

Figure 7 shows the confocal laser microscope images obtained by in-situ observation of the carburizing and decarburizing reactions of the specimen surface (Specimen A) at $1073 \mathrm{~K}$. Initially, the phase of the specimen surface was $\alpha$ phase as seen in Fig. 7(a). As the carburizing reactions began, the $\gamma$ phase appeared from the triple junctions or along the grain boundaries as seen in Fig. 7(b). Finally, the surface of the specimen was fully covered by $\gamma$ phase grains as seen in Fig. 7(c). During the decarburizing reaction, the $\gamma$ phase grains was transformed into $\alpha$ phase grains as seen in Fig. 7(d). This in-situ observation image shows how the phases are transformed into the other phases. However, the

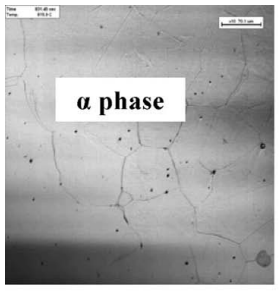

(a)

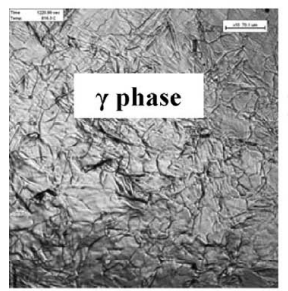

(c)

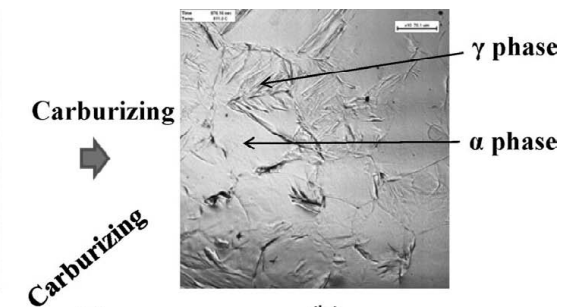

(b)

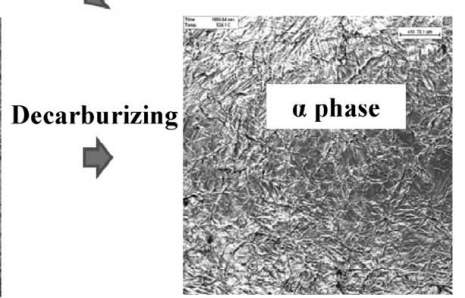

(d)
Fig. 7. In-situ observation of $\alpha \rightarrow \gamma \rightarrow \alpha$ transformations by CSLM. (a) Optical micrograph before carburizing. (b) Optical micrograph during carburizing. (c) Optical micrograph after carburizing. (d) Optical micrograph after decarburizing. grain size change was not detected by this observation, because the grain boundaries were not distinguished due to the surface roughing after the phase transformation.

\subsection{Effect of Sulfur on Ferrite Grain Refinement}

It is well known that solute atoms will retard the grain growth by so-called solute drag effect. ${ }^{5-7)}$ Sulfur is a strong surface active element so that it will concentrate in the grain boundary and possibly retards the grain growth. ${ }^{5,6)}$ As a first step, the effect of $S$ on the grain growth retardation has been investigated. Figure 8 shows the grain structures on the surfaces of the specimen A (S: 9 ppm), B (S: 20 ppm) and C (S: $58 \mathrm{ppm}$ ) after 3times repeated carburizing and decarburizing reactions at $1073 \mathrm{~K}$. Figures 8(a)-8(c) corresponded the specimen $\mathrm{A}, \mathrm{B}$ and $\mathrm{C}$ respectively. The initial grain sizes of the specimens A, B and C at $1073 \mathrm{~K}$ were 120,80 and $60 \mu \mathrm{m}$, respectively. The final ferrite grain sizes were found to be $32 \mu \mathrm{m}, 29 \mu \mathrm{m}$ and $31 \mu \mathrm{m}$. The grain size was evaluated based on the grain counting method. Namely, the number of grains per unit area is counted directly and converted into the average size corresponded to a circle.

Figures $8(\mathrm{~d})$ and $8(\mathrm{e})$ show the grain structure of the surface of the specimen $\mathrm{B}$ and $\mathrm{C}$ after 6 times repeated carburizing and decarburizing reactions at $1073 \mathrm{~K}$. Even after 6 times repeated carburizing and decarburizing reactions, the grain sizes did not decrease anymore but rather slightly increased. Namely, S content has no effect on the grain growth retardation against our expectation. These results suggested that the grain sizes do not decrease once they reach to the grain size of about $30 \mu \mathrm{m}$.

To find out the reason of the limitation of the grain refinement, the grain sizes after each carburizing and decarburizing reaction were examined. Figure 9 shows how the grain sizes of the specimen A (S: 9 ppm) changed after each carburizing and decarburizing reaction at $1073 \mathrm{~K}$. In this experiment, the initial grain size was adjusted to about $300 \mu \mathrm{m}$ to observe the grain size change clearly. The grain sizes were

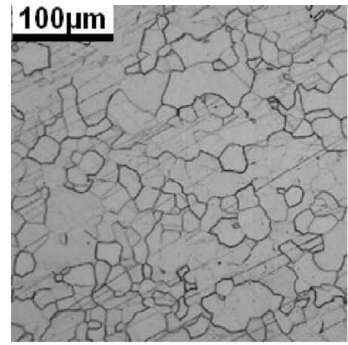

(a)

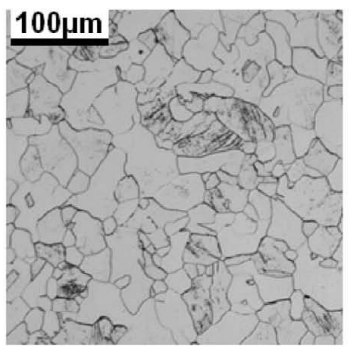

(b)

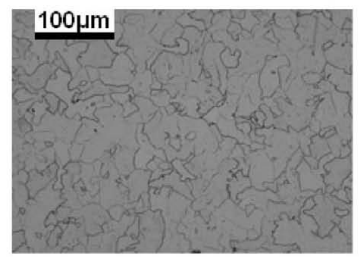

(d)

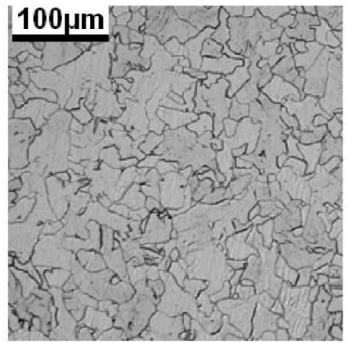

(c)

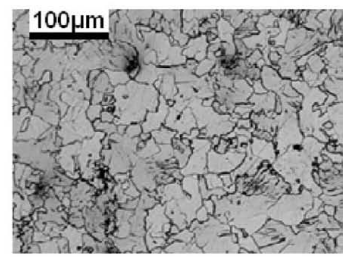

(e)

Fig. 8. Optical micrograph showing grain distribution after 3 and 6 times repeated carburizing and decarburizing reactions. (a) Specimen A (9 ppm sulfur) - 3 times repetition. (b) Specimen B (20 ppm sulfur) - 3 times repetition. (c) Specimen C (58 ppm sulfur) - 3 times repetition. (d) Specimen B (20 ppm sulfur) - 6 times repetition. (e) Specimen B (58 ppm sulfur) -6 times repetition. 


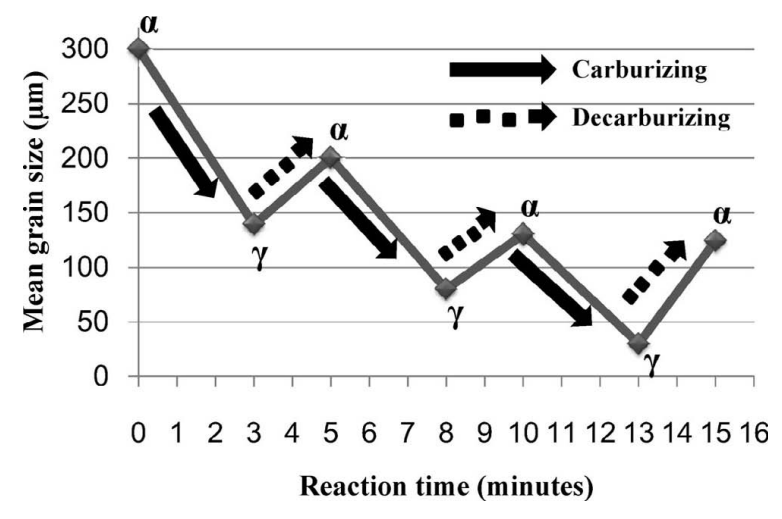

Fig. 9. Change of mean grain size by repeated carburizing and decarburizing reactions.

decreased by the carburizing reactions and increased by the decarburizing reactions. When the grain size is large, the degree of grain size decrease due to the carburization is dominant than that of the grain size increment due to the decarburization. With decreasing the grain size, however, both degrees become comparable. As a result, the final ferrite grain sizes are limited to about $130 \mu \mathrm{m}$ if started from the initial grain size of $300 \mu \mathrm{m}$.

Consequently, the repeated carburizing and decarburizing reactions was not so effective to reduce the grain size less than $30 \mu \mathrm{m}$. Even though the sulfur content increased, the final ferrite grain sized did not decrease.

\subsection{Effect of Cementite on Grain Refinement (Speci- men A)}

As shown in the previous experiment, sulfur had negligible effect on the retardation of grain growth during $\alpha$ to $\gamma$ phase transformation so that simply repeating carburizing and decarburizing reactions was not effective for decreasing the ferrite grain sizes because the grain sizes were increased by the decarburization step. Not only the solute drag, however, but also the pinning effect due to the disperse particles is known to retard the grain growth. ${ }^{8-11)}$ As an alternative approach to retard the grain growth, an effective use of cementite precipitation has been investigated.

Figure 10 shows the optical microscope images of specimen A, obtained after the repeated carburizing and decarburizing experiment with cementite formation by using the additional heat treatment described in Fig. 4. The annealing temperatures (cementite forming temperature) were $673 \mathrm{~K}$ in Fig. 10(a) and $873 \mathrm{~K}$ in Fig. 10(b), respectively. It is shown that there are the small ferrite grains surrounded by cementite bands (Fig. 10(a)) and also small grains near the cementite precipitates (Fig. 10(b)). From these results, it is suggested that the existence of cementite may help to retard the grain growth during the carburizing and decarburizing reactions. Namely, the grain growth retardation by the pinning effect due to the dispersed $\mathrm{Fe}_{3} \mathrm{C}$ is found to be more effective than that by the solute drag by $\mathrm{S}$. The difference between them can be explained by the comparison of each retardation force evaluation based on the proposed several models. ${ }^{5-9)}$ However, the aim of this study is to qualitatively demonstrate the possibility of the grain refinement by the repetitive carburization and decarburization reactions. Thus, the details of the difference will be left for the future study.

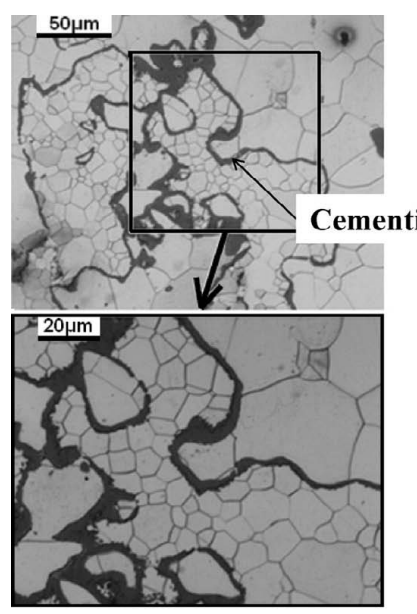

(a) $673 \mathrm{~K}$

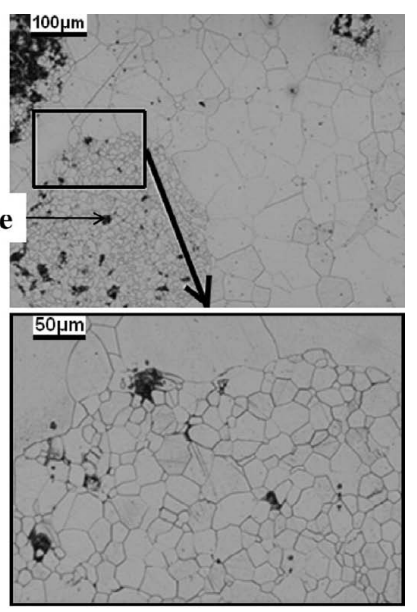

(b) $873 \mathrm{~K}$
Fig. 10. Optical micrograph showing grain distribution of specimen A after carburizing and decarburizing reactions with cementite formation. (a) annealing at $673 \mathrm{~K}$. (b) annealing at $873 \mathrm{~K}$.

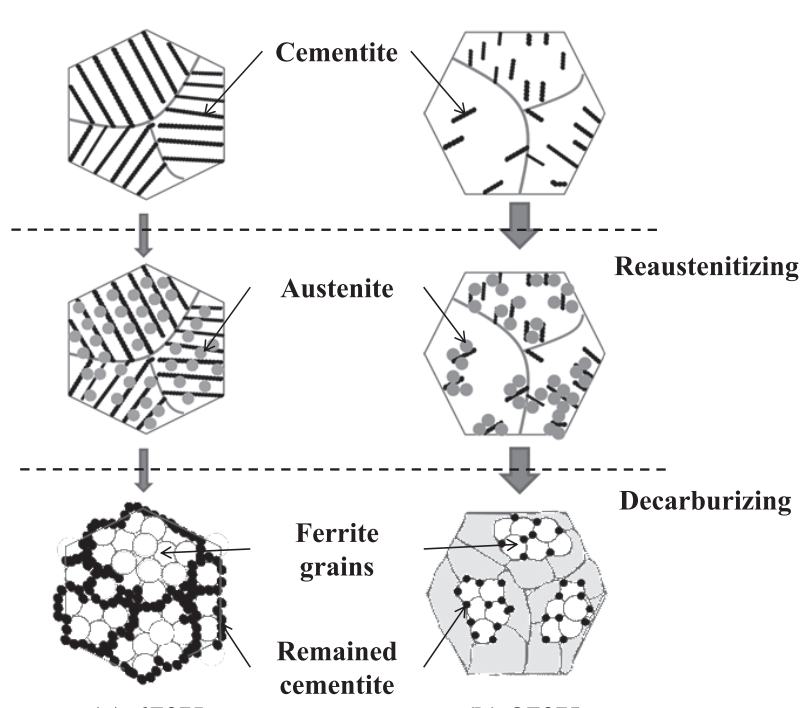

(a) $673 \mathrm{~K}$

(b) $873 \mathrm{~K}$

Fig. 11. Schematic illustration showing the effect of cementite on ferrite grain refinement. (a) annealing at $673 \mathrm{~K}$. (b) annealing at $873 \mathrm{~K}$.

Figure 11 illustrates the possible mechanism how the different cementite structure causes the different final ferrite structure shown in Fig. 10. A large amount of cementite is formed at $673 \mathrm{~K}$ treatment and they initiate austenite nucleation but the austenite grains were trapped by the cementite precipitates during the reaustenitizing processing at $1073 \mathrm{~K}$. Figure 12 shows the cementite bands on austenite matrix during reaustenitizing process.

During the decarburizing reactions, relatively large amount cementite precipitates possibly remained in nondissolved state preventing ferrite grain growth at $673 \mathrm{~K}$. In case of $873 \mathrm{~K}$ treatment, however, the amount and size of formed cementite were small so that most of cementite was disappeared during decarburization process and less effect for preventing the grain growth. These results suggest that the grain refinement of less than $30 \mu \mathrm{m}$ can be established if the relatively stable cementite precipitates are evenly dispersed in the matrix. 


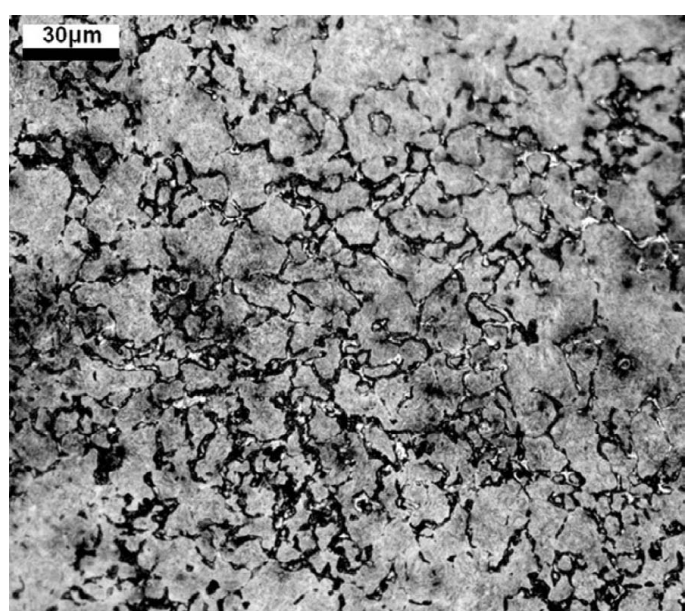

Fig. 12. Optical micrograph showing grain distribution and cementite band of specimen A on austenite matrix formed by $673 \mathrm{~K}$ annealing.
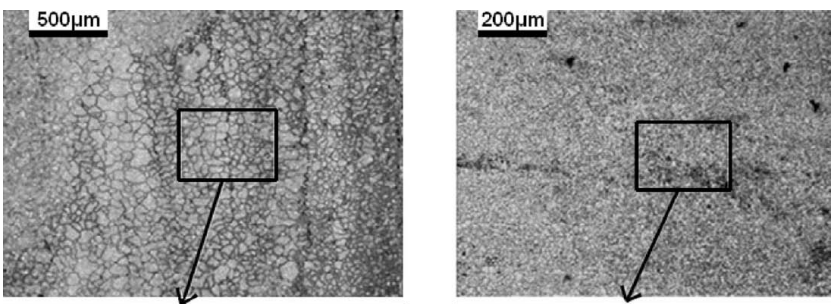

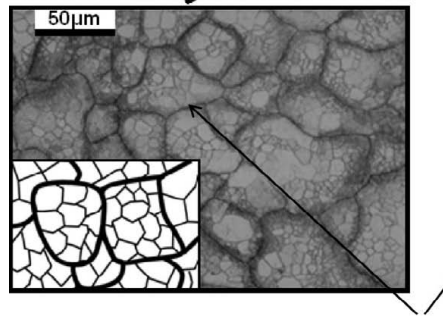

(a) $673 \mathrm{~K}$
Cementite

(b) $873 \mathrm{~K}$
Fig. 13. Optical micrograph showing grain distribution of specimen D after carburizing and decarburizing ( $2 \mathrm{~min}$.) reactions with cementite formation. (a) annealing at $673 \mathrm{~K}$. (b) annealing at $873 \mathrm{~K}$.

\subsection{Effect of Manganese on Grain Refinement (Speci- men D)}

It is well known that $\mathrm{Mn}$ can form alloyed $\mathrm{Fe}_{3} \mathrm{C}$ and stabilize it. ${ }^{12)}$ Therefore, the addition of $\mathrm{Mn}$ in specimen may prevent the rapid ferrite grain growth by the stabilized $\mathrm{Fe}_{3} \mathrm{C}$ precipitates. In order to confirm this assumption, the grain refinement process with the cementite introduction process was applied for the commercial high carbon steel (specimen D). Strictly speaking, the effect of $\mathrm{Mn}$ addition on the grain refinement should be evaluated by the comparison between the sample A and that with Mn addition. Due to some difficulties of sample preparation, the commercial high carbon steel was tentatively used in this study since it contains high Mn of 0.7 mass $\%$.

Figure 13 shows the refined ferrite structure obtained by carburizing (3 min.) and decarburizing $(2 \mathrm{~min}$.) reactions with annealing process ( $5 \mathrm{~min}$.). The annealing temperatures is $673 \mathrm{~K}$ (Fig. 13(a)) and $873 \mathrm{~K}$ (Fig. 13(b)). The fine cementite bands and precipitates were widely distributed and the grain refinement occurs evenly on the whole surfac-

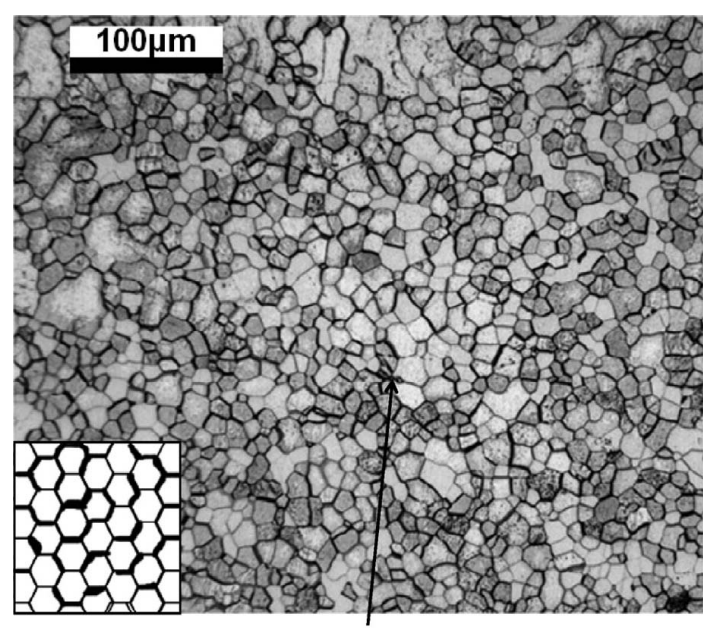

\section{Cementite}

Fig. 14. Optical micrograph showing grain distribution of specimen D after carburizing and decarburizing (3 min.) reactions with cementite formation.

es. The mean grain sizes were less than $10 \mu \mathrm{m}$. It simply means that the cementite becomes more stable with the addition of $\mathrm{Mn}$ and relatively large amount of cementite is still existed in the matrix even after the decarburization. To decrease the cementite volume, the decarburization time is increased from $2 \mathrm{~min}$. to $3 \mathrm{~min}$. Figure 14 shows the ferrite grain structure after decarburizing reactions $(3 \mathrm{~min}$.) at $1073 \mathrm{~K}$. It is shown that the most of the grain size were around $10 \mu \mathrm{m}$ and the shapes of the grains were very regular and uniform that was quite different from ones shown in Fig. 8. The cementite is existed between the ferrite grains. These regular and uniform shapes indicate that the ferrite grains are well stabilized even though the sizes are small. From these results, fine ferrite grains of less than $5 \mu \mathrm{m}$ will be possibly produced by the repeated carburizing and decarburizing processing combined with adjusting the cementite size and its whole volume.

The present study suggests the retardation effect of $\mathrm{Mn}$ addition on the grain growth, however, further work for the effect of $\mathrm{Mn}$ on the grain refinement, possibly by studying the grain growth in the sample with and without Mn addition, is needed to provide the quantitative information of the effect of $\mathrm{Mn}$ addition on the grain refinement.

\section{Conclusions}

In the present study, the possibility of grain refinement of $\alpha$-Fe by repeated carburizing and decarburizing processing has been investigated. The main conclusions are summarized as follows.

(1) Grain size decreases by $\alpha \rightarrow \gamma$ phase transformation on carburizing reaction, while it increases by $\gamma \rightarrow \alpha$ on decarburizing reaction.

(2) As the grain sizes become small, the grain size decreasing rate by carburizing and the grain size increasing rate by decarburizing becomes comparable. As a result, the final ferrite grain size is limited to be around $30 \mu \mathrm{m}$ even after 6 times repeated carburizing and decarburizing processing.

(3) The retarding effect on the grain growth by sulfur is 
not strong enough to hold the grain size less than $30 \mu \mathrm{m}$.

(4) The combination of the carburizing and decarburizing processing and the cementite introduction by annealing at $673 \mathrm{~K}$ can produce the fine $\alpha$-Fe grain of with less than $10 \mu \mathrm{m}$. The undissolved cementite during reaustenitization may supply a lot of nucleation sites during reaustenitizing process and also it retards ferrite grain growth during $\gamma \rightarrow$ $\alpha$ transformation process by decarburizing reaction.

\section{REFERENCES}

1) W. D. Callister: Fundamentals of Materials Science and Engineering, 27th ed., Wiley \& Sons., New York, (2007), 189.

2) Y. Weng: Ultra-Fine Grained Steels, 1st ed., Springer, New York,
(2009), 19.

3) R. A. Grange: Metall Trans., 2 (1971), 65

4) G. H. Geiger and D. R. Poireir: Transport Phenomena in metallurgy, Addison-Wesley, New York, (1973), 490.

5) K. Lucke and K. Detert: Acta Metall., 5 (1957), 628.

6) J. W. Cahn: Acta Metall., 10 (1962), 789.

7) M. Hillert: Metall Trans. A, 6A (1975), 5.

8) F. J. Humphreys and M. Hatherly: Recrystallization and related annealing phenomena, Elsevier, New York, (1995), 73.

9) T. Nishizawa, I. Ohnuma and K. Ishida: Mater. Trans., JIM, 38 (1997), 950.

10) N. Moelans, B. Blanpain and P. Wollants: Acta Mater., 54 (2006), 1175 .

11) M. Militzer: Metall. Mater. Trans. A, 27A (1996), 3399.

12) M. Umemoto, Z. G. Liu, K. Masuyama and K. Tsuchiya: Scr. Mater., 45 (2001), 391. 